\title{
The need to consider the predictive capacity of intelligence and its malleability within design and technology education research
}

\author{
Jeffrey Buckley ${ }^{1,2}$ (D)
}

Accepted: 7 May 2020 / Published online: 14 May 2020

(c) The Author(s) 2020

\begin{abstract}
General intelligence is a fundamental human capacity with significant educational implications. However, it is often not considered in educational research despite substantial evidence illustrating its association with positive life outcomes and student's capacity to learn. There are a number of potential reasons for this including the controversial history of the use of intelligence tests, validity concerns, counter-moral implications associated with equality, lack of related training, and discipline research priorities. Design and technology (D\&T) education however presents a subject area where consideration of student's intelligence appears particularly important. The focus on design provides students with regular variation learning contexts, with a similar phenomenon occurring through the subject areas focus on technology as a result of constant cultural and societal technological advances. However, intelligence is rarely considered within D\&T education research. Therefore, this article puts forward an argument and rationale as to why D\&T researchers need to give more consideration to the predictive value of general intelligence and its malleability in pertinent research and discusses some implications for intelligence in practice.
\end{abstract}

Keywords Intelligence $\cdot$ Design and technology education $\cdot$ Cognitive factors $\cdot$ Research design

\section{Introduction}

Intelligence research and the use of intelligence tests has a controversial history. The eugenics movement for example was abhorrent. Furthermore, evidence associated with intelligence can often run counter to people's inherent moral values concerning equality, especially from an educational perspective. For example, there is much evidence indicating sex differences in intelligence factors (Halpern 1997; Halpern and LaMay 2000; Voyer et al. 2017) and there has been and continues to be significant discourse pertaining to racial

Jeffrey Buckley

jbuckley@kth.se

1 Department of Learning, KTH Royal Institute of Technology, Stockholm, Sweden

2 Faculty of Engineering and Informatics, Athlone Institute of Technology, Westmeath, Ireland 
implications associated with intelligence test scores, particularly following the publication of Herrnstein and Murray's (1994) The Bell Curve: Intelligence and Class Structure in American Life. However, a controversial history and findings which may be unappealing do not provide cause to discount the substantive evidence that does exist. Negative educational consequences can arise through the misuse of intelligence evidence, as they can through the misappropriation of most evidence. For intelligence in particular this is evident with respect to inequality and discrimination. What is needed is awareness and consideration of state-of-the-art evidence from intelligence research as it relates to education, with discussion on its utility grounded within empirical, philosophical, sociological, and ethical frameworks. In light of current evidence, this article aspires to discuss some of the reasons why and how intelligence should and could be considered specifically within design and technology (D\&T) education research. It is recommended specifically that intelligence, including individual factors of intelligence, requires initial investigation with respect to its predictive capacity for desirable D\&T educational outcomes such as student performance, interest, motivation, and learning benefit in association with specific pedagogies. This would permit the finding of pedagogical solutions that work well in context, and the ruling out of those unlikely to be of benefit (Maranto and Wai 2020). Further to this, a complementary agenda would be an exploration of the potential of D\&T education and educators to support the development of intelligence, for which a speculative commentary is provided later in the text.

\section{Defining and describing intelligence}

To describe why and how intelligence should become more of a focus within D\&T research, a working definition which bounds what is meant by the term intelligence within this discussion is necessary. Meehl (2006, p. 435) notes that "verbal definitions of the intelligence concept have never been adequate or commanded consensus". This is due to the complexity of the construct. While there is some degree of consensus that intelligence at least partially involves the ability to adapt to one's environment (Neisser et al. 1996; Sternberg 2019), there is no comprehensive verbal definition which is agreed upon amongst experts and it is therefore beyond the remit of this article to present one. There are however many descriptions which are used, often contextualised to the subject at hand and relative to a particular field of study, of which there are many, e.g., neurological, anthropological or psychometric (see Sternberg 2000). Further, within different fields there are different theoretical frameworks for intelligence, such as cultural intelligence (Ang and van Dyne 2008), practical intelligence (Sternberg et al. 2000), emotional intelligence (Mayer and Salovey 1993) and social intelligence (Thorndike and Stein 1937).

Intelligence research associated with psychometrics has arguably the largest body of educationally relevant evidence from which to draw from. In this area, researchers use psychometric instruments to measure specific factors of intelligence or a general intelligence/ general cognitive ability factor. These instruments often take the form of paper and pencil based tests in areas such as mathematics, verbal and spatial ability as well as processing speed and working memory capacity, but in recent times there has been a shift towards computerised variants. The psychometric construct of a general cognitive ability known as $g$ (Spearman 1904) is also arguably the most replicated result in all of psychology (Deary 2000). Therefore, this article will relate specifically to the traditional view of intelligence 
which comprises of a single general ability, $g$, under which a hierarchical structure of progressively more specific levels of abilities exists.

In consideration of Meehl's comment that verbal definitions have proven inadequate, intelligence within the psychometric tradition is perhaps best described empirically. Validated cognitive factors and the relationships between them are themselves the definition. Although it has critics, (Canivez and Youngstrom 2019; Johnson and Bouchard Jr. 2005; Major et al. 2012), the Cattell-Horn-Carroll (CHC) theory (Schneider and McGrew 2018) is currently the most comprehensive and widely supported framework describing the structure of human cognitive abilities (Savi et al. 2019). In the CHC theory, cognitive factors are positioned across three hierarchical strata (see Fig. 1 for an example). First-order cognitive factors are specific mental abilities, directly measurable with psychometric instruments. The first-order factor of visualization, describable as "the ability to perceive complex patterns and mentally simulate how they might look when transformed (e.g., rotated, changed in size, partially obscured)" (Schneider and McGrew 2012, p. 129) can serve as an example. Visualization is often measured with instruments such as the Purdue Spatial Visualization Test: Rotations (PSVT:R; Guay 1977) which involves the mental rotation of relatively complex 3-dimensional abstract objects and this factor has been seen already, albeit rather sparsely, in D\&T related education research (Buckley et al. 2018b; Liao 2017; Lin 2016). Second-order cognitive factors are measurable through instruments which contain a variety of indicators of associated first-order factors. For example, the second order factor of spatial ability can be described as "the ability to make use of simulated mental imagery (often in conjunction with currently perceived images) to solve problems" (Schneider and McGrew 2012, p. 129) but can be defined as a latent variable loaded on by a collection of first-order spatial factors such as visualization, speeded rotations and closure speed (Buckley et al. 2018a; Carroll 1993; Schneider and McGrew 2018). Therefore, to ascertain a measure of spatial ability in practice, an instrument containing multiple items associated with the various first-order factors associated with it is needed. In such an event, a composite score is then generated based on the various measures relating to first-order factors, and it is this score which would represent an approximation of spatial ability. Finally, general cognitive ability, the single third-order cognitive factor, shares the same hierarchical relationship with second-order factors as second-order factors do with first-order factors.

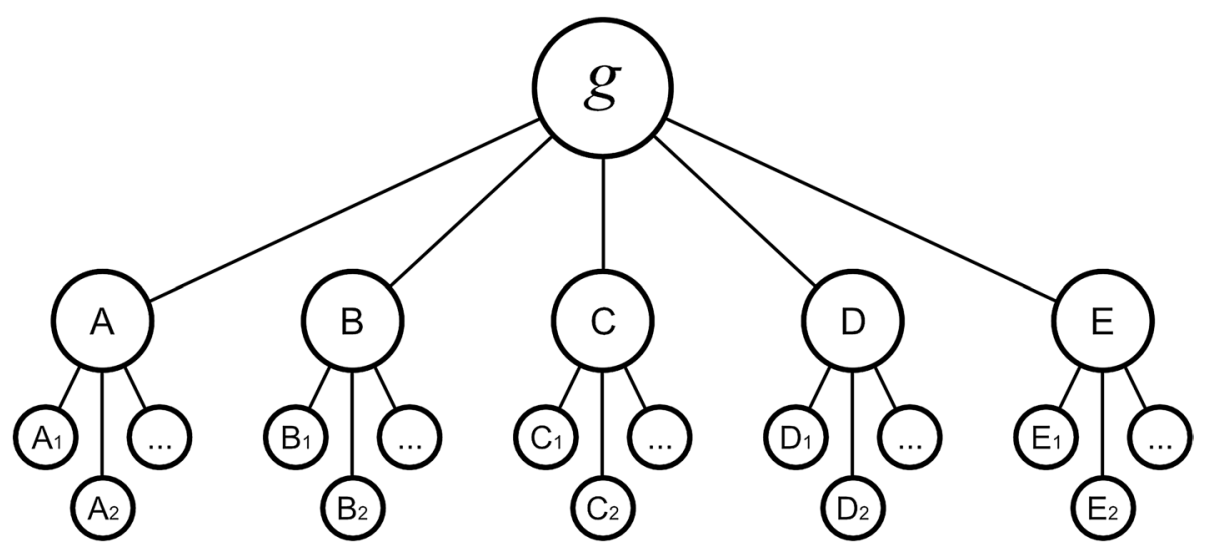

Fig. 1 Generic diagram of a hierarchical factor model containing three strata, with general cognitive ability (g) as a third-order factor 
In practice, full-scale IQ tests such as the Wechsler Adult Intelligence Scale (WAIS) are designed based on this framework. The fourth, and most recent version of this test, the WAIS-IV contains ten core subtests (which align with first-order factors) across four indices (which relate to second-order factors). The outputs from this include performance on each subtest, index, and by considering all ten subtests a measure of full scale IQ is derived, which is an approximation of general intelligence.

There are a number of notable aspects to this particular model. The CHC theory currently contains 84 first-order factors, 16 second-order factors, and a single third order factor. It was developed through as synthesis of the Gf-Gc theory (Cattell 1943, 1963) which itself was developed (Cattell and Horn 1978; Horn 1985; Horn and Cattell 1966; Horn and Noll 1997) by drawing on evidence from "neurological damage and aging" and "genetic, environmental, biological, and developmental variables" (Horn and Blankson 2005, p.45), and Carroll's (1993) three-stratum theory which was the result of a meta-analysis of 461 psychometric datasets and which was the first empirically based taxonomy that presented all established cognitive factors into a single organised framework (McGrew 2009). So while there are opponents to this theory, the general structure is supported by decades of empirical research, and while it is refined over time, this activity generally relates to the addition of new factors which emerge as a greater understanding of the human cognitive architecture is gained.

Additionally, while first-order factors are associated with specific second-order factors, such as the visualization factor being associated with spatial ability, they also correlate with other second-order factors. All factors of intelligence, or performance on tests of cognitive ability, tend to correlate positively with each other in a phenomenon known as the positive manifold (Savi et al. 2019; Spearman 1904) and it is this positive manifold that was the basis of Carroll's (1991) understanding of general intelligence. Visualization, for example, correlates with the second-order factor of fluid intelligence (Buckley et al. 2018a, $\mathrm{b}, \mathrm{c}, \mathrm{d})$ which is a multidimensional construct describable as "the deliberate but flexible control of attention to solve novel, "on-the-spot" problems that cannot be performed by relying exclusively on previously learned habits, schemas, and scripts" (Schneider and McGrew 2012, p. 111), but this is a weaker relationship than its correlation with spatial ability. In fact, the first-order factor of visualisation is the closest, i.e., strongest correlating, first-order factor to spatial ability (Carroll 1993), and the second-order factor of fluid intelligence is the closest second-order factor to general intelligence (Ebisch et al. 2012). An important implication of this for practice is that to provide a valid approximation of a specific first-order cognitive factor, a variety of tests, most often three, known to correlate strongly are used and a composite score is taken as the indicator, and this approach is then expanded to second-order factors and when measuring general intelligence. This approach mitigates issues associated with task related biases and validity, as an increased number of measures can be triangulated to reduce error, however all measures are still generally considered as approximations. The groupings within the $\mathrm{CHC}$ theory are based on the strengths of these correlations, and what is presented in Fig. 1 is a simplistic schematic for explanatory purposes of the different strata.

In summation, it is advocated that the most appropriate working definition for intelligence for the purposes of this article is the empirical model presented through the $\mathrm{CHC}$ theory. That is, intelligence in practice should be conceived relative to the instruments used to assess it, as no single verbal definition will be sufficiently comprehensive. With respect to offering a verbal description intelligence, it is considered most appropriate to align with that which is offered by the synthesisers of the $\mathrm{CHC}$, that intelligence or $g$ is "not an ability itself, but the sum of all forces that cause abilities within the same person to be more 
similar to each other than they otherwise would have been" (Schneider and McGrew 2012, p. 103).

\section{Contemporary perspectives on the context of design and technology education}

D\&T education, a term used here in an inclusive capacity for the various ways that design and/or technology education manifests internationally, is a relatively unique subject area from a teaching and learning perspective. This is due in part because of the inclusion of design and in part because of the focus on technology. It is important to note at this stage that both the terms design and technology here are used in a broad capacity, but still within the confines of D\&T. Technology is considerable relative to objects, knowledge, activity and volition (Mitcham 1994), and design in this instance relates to its varied pedagogic use in D\&T classrooms. While specific syllabi within national curricula have discrete and unique learning outcomes, international discourse positions the function of D\&T education quite broadly, for example in terms of the development of technological capability (Gibson 2008), technological literacy (Ingerman and Collier-Reed 2011; Williams 2009), and/ or technological perspective (Barlex and Steeg 2017). D\&T education, as a result, can be described as having a fluid epistemological boundary (Norman 2017) as there is an inherent response to societal and cultural technological advances. D\&T as a subject area permits and encourages learners to engage with scientific and technological advances which emerge even after the publication of policy documents such as syllabi and specifications. This is perhaps most evident through social media accounts of D\&T researchers and practitioners who post content, often in the form of case studies, which may be of interest to those teaching and learning in D\&T (e.g. @DavidBarlex and @ teknikpedagog via Twitter). Furthermore, when considering design and the pursuit of nurturing the designerly (Stables 2008), D\&T learners regularly face considerable openness in their learning endeavours resulting in significant variance in learners educational experiences between classrooms (Atkinson 2017). A direct result of this openness was the need to reconceive the nature of assessment practices in D\&T to be able to account for "learners [being] excellent in design and technology in dramatically different ways" (Kimbell 2007, p. 67). Hence, adaptive comparative judgement (ACJ) was developed (Kimbell 2012; Kimbell et al. 2005, 2007, 2009; Pollitt 2012a, b).

This combination of the dimensions of design and technology within D\&T, albeit possible to various degrees (Barlex 2019), means that students must regularly engage with problem solving scenarios which are quite novel, and the capacity for having relevant prior knowledge can, at times, be uncertain. The distinction between knowledge of the problem, i.e. knowledge which is "specific to the problem being addressed and needs to be found by exploring the situation in which the problem is embedded" and knowledge for the solution, i.e., knowledge which "for any domain of design \& technology... does not change as the design task changes" goes some way towards scaffolding gaps in prior knowledge (Barlex and Steeg 2017, pp. 16-17). It is knowledge of the problem where prior knowledge is less likely to exist as learners engage with design activities from varying contexts, or conceive solutions which guide their investigations along novel pathways. However, as with all subject areas knowledge for the solution can also see deficits in prior knowledge, a gap which ought to be reconciled by students before or during the learning activity. 
The inherent openness and uncertainty which must often be negotiated by learners within D\&T due to the nature of knowledge of the problem and the engagement in designerly activity provokes two lines of discourse. The first is that the status of D\&T education from a policy perspective can be negatively affected as there is less clarity surrounding the subject in terms of epistemology, purpose and practice (Barlex and Steeg 2017). The second is that the applied nature of technological knowledge necessitates a different pedagogical approach to subjects constructed less prominently around the application of knowledge in context (Buckley et al. 2018d; de Vries 2016). This line of dialogue has seen suggestions for the integration of design thinking more thoroughly within D\&T education (Spendlove 2017) and the need to consider signature pedagogies, such as demonstrations (McLain 2018, 2019) and critique (von Mengersen 2017) within D\&T. Additionally, while not an exhaustive list, four recent publications offer further clarity surrounding contemporary perspectives on D\&T research. Williams et al.'s (2015) edited volume The Future of Technology Education contains contributions from a variety of prominent D\&T academics, and was developed with the purpose of mapping an agenda for D\&T education moving forward. Williams and Barlex's edited volumes Contemporary Research in Technology Education: Helping Teachers Develop Research-Informed Practice (2017) and Explorations in Technology Education Research: Helping Teachers Develop Research Informed Practice (2019) contain contributions from recent PhD graduates in D\&T. Finally, a review article by Xu et al. (2019) provides a quantitative review of demographic information of technology education researchers, as well as details of seminal works. Across these publications, with the exception of one chapter associated with a $\mathrm{PhD}$ project (Khoza 2017), there is no reference made to human intelligence or an intelligence related construct within any of these publications. Khoza (2017) considered visualization as indicated by the PSVT:R test (Bodner and Guay 1997; Guay 1977) in a study aimed at exploring the difficulties faced by university students in learning sectional drawing in a South African university. In anticipation of the ensuing discussion on why intelligence merits further recognition within perspectives on the future of D\&T research, these texts illustrate that currently it largely does not feature. While this is perhaps due to D\&T research agendas often evolving in response to issues emerging from practice (Seery et al. 2019), it is argued that there is now need to further emphasise affecting practice as a result of foundational research, particularly from the perspective of intelligence.

\section{Why intelligence merits greater consideration within D\&T research}

Three ideas were initiated in the previous section regarding D\&T:

1. Knowledge acquisition: There is a focus on technology which sees learners needing to acquire knowledge and that this often goes beyond policy specifications due to scientific and technological developments,

2. Design and knowledge application: Designerly activity within D\&T can lead to learners operating in a natural space of uncertainty, and a dichotomy of knowledge of the problem and knowledge for the solution can exist,

3. Purpose: That difficulties in clarifying the specific remit of D\&T with respect to epistemology, purpose and practice exist, but that the subject has an applied which requires commensurate pedagogies. 
These will be expanded further to present avenues for how intelligence research could benefit D\&T education research.

\section{Knowledge acquisition}

Generally, a strong relationship between general intelligence and academic achievement is well established (Carroll 1997; Frey and Detterman 2004; Jensen 1998; Koenig et al. 2008; Maranto and Wai 2020). Indeed, it is often argued that intelligence tests are measures of some form of academic intelligence (Ritchie 2015). There are a number of caveats to this. A strong relationship between two variables does not necessarily indicate that they are the same, or that the measurement instruments are too similar. There can be mechanistic relationship, which in this case would mean inferring intelligence is a mechanism behind educational outcomes or vice versa. This has direct application within D\&T research as there is an inevitable focus on learning which is defined as being "a change in long-term memory" (Kirschner et al. 2006, p.75) that "involves the acquisition of knowledge" (Mayer 2002, p. 226). As D\&T students regularly must acquire knowledge of varying types, any factor which effects learning processes ought to be acknowledged in this capacity within pertinent research agendas. It has been found that intelligence supports the acquisition of knowledge (Kvist and Gustafsson 2008; Primi et al. 2010) and that assessments of student educational achievement are often measures of "cumulative processes of knowledge acquisition" (Baumert et al. 2009, p. 174). Additionally, Baumert et al. (2009) delineate the conceptual differences between tests of cognitive ability and student academic achievement. Based on this line of evidence, it can be inferred that intelligence moderates peoples capacity to acquire knowledge and that this is a reason behind its strong relationship with educational achievement.

To further emphasise the difference between tests of cognitive ability and test of student educational achievement, it is important to acknowledge that intelligence also has a positive relationship with a number of other competencies and life outcomes. These include creativity (Nusbaum and Silvia 2011) and the sensory ability to discriminate musical rhythms and tones (Mosing et al. 2014), attributes which are further removed from academic achievement than intelligence, and also risk perception, conscientiousness, happiness, mental health, and living longer (Ritchie 2015). Taken together all of these further suggest that intelligence tests are not exactly the same as measures of student performance, which aligns with the working description being adopted that intelligence is the "sum of all forces that cause abilities within the same person to be more similar to each other than they otherwise would have been" (Schneider and McGrew 2012, p. 103).

There are also a number of other factors impacting educational performance which further illustrate that measures of intelligence and academic performance are not isomorphic. These variables can broadly be considered within two categories, student variables and school variables (Detterman 2016). Student variables include characteristics inherent to individual students such as intelligence, self-efficacy, grit, motivation, socioeconomic status, and parent or guardian education. School variables include the characteristics of schools that effect groups of students within them such as teacher quality, whole class teaching, learning and assessment activities, length of the school day, class size, and money spent per student. Detterman (2016) reviewed evidence accumulated over the past 50 years and found that approximately $10 \%$ of the variance in academic achievement at every level of education in developed countries can be attributed to school variables, while approximately $90 \%$ of the variance can be attributed to student variables. Detterman (2016) 
noted that teachers account for between 1 and $7 \%$ of the total variance in academic achievement while general cognitive ability or intelligence accounts for somewhere between $\mathbf{5 0}$ and $80 \%$ of the total variance, for which corroborating evidence has subsequently been found (O'Connell 2018; Smith-Woolley et al. 2018). Based on this effect size, it is recommended that D\&T research which relates to knowledge acquisition has at least a peripheral acknowledge of potential underlying cognitive abilities moderating participant outcomes.

\section{Design and knowledge application}

The concept of 'knowing', as a direct result of the subject area dealing with technological knowledge which is applied, normative, and context specific (de Vries 2016) while negotiating designerly problems, is often uniquely formulated in D\&T. This is not to suggest that the acquisition of scientific, or indeed other forms of declarative, conceptual, procedural, conditional or causal knowledge does not occur or is not important within the subject area, but that the purpose of acquiring such knowledge and the associated functions for its use are often contextually different in D\&T than many other subject areas. By way of example, Kimbell $(2011$, p. 7) notes that learners are empowered "to take action with provisional knowledge" while operating in an "intermediate zone of activity where hunch, half-knowledge and intuition are essential ingredients" as D\&T education has "transposed the issue of 'knowing stuff' into the business of 'finding-out-about' stuff'. This sentiment is echoed by other D\&T researchers such as Williams $(2000,2009)$ who notes that "the domain of knowledge as a separate entity is irrelevant; the relevance of knowledge is determined by its application to the technological issue at hand. So the skill does not lie in the recall and application of knowledge, but in the decisions about, and sourcing of, what knowledge is relevant" (Williams 2009, pp. 248-249).

Reverting back to the discourse on knowledge of the problem, which is problem specific, within the realm of D\&T designerly activity sees students regularly becoming more contextually novice (albeit perhaps temporarily) despite continuously acquiring knowledge. For such novice learning in D\&T, intelligence research associated with the circumventionof-limits hypothesis is of particular pertinence (Salthouse 1991). The circumvention-oflimits hypothesis holds that "the effect of domain general abilities and capacities on performance diminishes as skill in a task is acquired through training" (Hambrick et al. 2018, p. 307) and stems from classic theories of skill acquisition (Fitts and Posner 1967). Figure 2 provides an illustration of the hypothesis which shows that for people with high knowledge as it relates to performance on a given task, general cognitive abilities have little to no impact on performance, whereas for those with low levels of related knowledge, higher levels of general cognitive abilities result in increased performance.

Evidence for the circumvention-of-limits hypothesis exists relative to geospatial mapping (Hambrick et al. 2012), chemistry (Stieff 2007) and physics (Kozhevnikov and Thornton 2006), and is therefore worth exploring in the context of D\&T. For example, while students can consistently become more expert in D\&T in terms of knowledge for the solution, they regularly fluctuate to being less expert in terms of knowledge of the problem as they engage in consecutive design tasks. As such, based on the circumvention-of-limits hypothesis, two hypotheses for D\&T can be generated. First that students who are more novice relative to knowledge for the solution, either at task, topic, or curricular levels, will rely more on relevant general cognitive abilities than those who are relatively more expert. Second, it is hypothesised that D\&T students need to more regularly rely on general cognitive abilities, or factors of intelligence pertinent to the task they are engaging with than 
Fig. 2 Circumvention-of-limits hypothesis (Salthouse 1991)

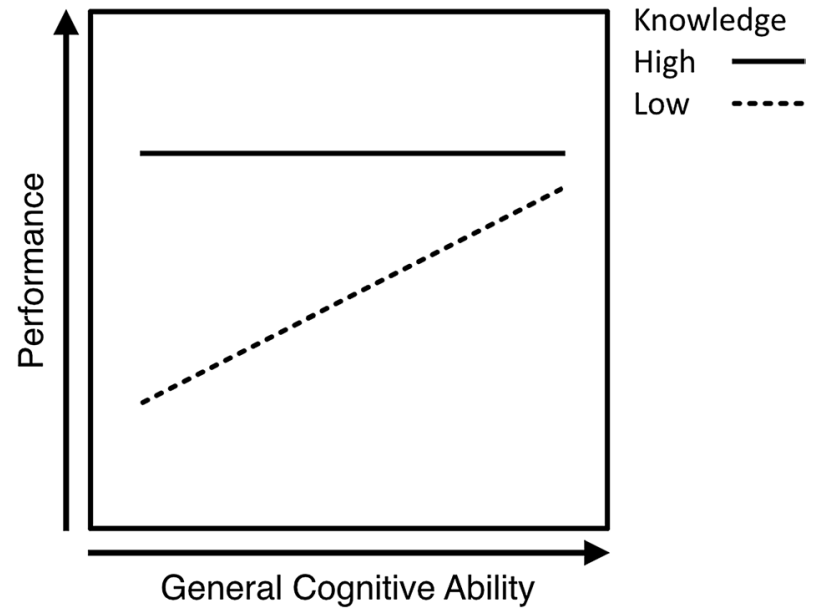

students of other less applied disciplines, specifically as a result of a higher frequency of educational activities requiring novice engagement with knowledge of the problem.

\section{Purpose}

Before reflecting on how intelligence could interact with a purpose of D\&T, it is important to note that substantial evidence suggests that intelligence cannot be meaningfully developed through targeted "brain training" interventions (Owen et al. 2010; Simons et al. 2016). Despite this, intelligence is not a fixed human capacity and this is true both at a human species level and on a generalised individual level. The Flynn effect refers to the observed rise in average IQ, an approximation of general intelligence, over time. Originally reported on in 1984 by Flynn, the Flynn effect describes an approximate rise in IQ by about three standardised points every decade (Flynn 1984), an effect size subsequently observed in a more recent meta-analysis (Trahan et al. 2014). This equates to an approximate increase of 0.2 standard deviations per decade (IQ scores are standardised to a mean of 100 and standard deviation of 15). Tucker-Drob (2009), in an examination of patterns of cognitive abilities across the life span, found a general trend that intelligence increases during childhood and decreases in adulthood from about the age of 20. Finally, Ritchie and Tucker-Drob (2018) through a meta-analysis involving 142 effect sizes from 42 datasets involving over 600,000 participants found consistent evidence that engaging with an additional year of education increases peoples IQ by approximately 1-5 standardised IQ points. Thus, formal education appears to be "the most consistent, robust, and durable method yet to be identified for raising intelligence" (Ritchie and Tucker-Drob 2018, p. 1358). A number of critical points can be inferred from this for further research within D\&T. Intelligence is not a fixed trait. While targeted "brain-training" style interventions have no impact on intelligence, educational interventions could. Even though the magnitude of effect size for intelligence developed through the Flynn effect and education may be considered small at an individual level, at a societal level there are substantial implications.

Translating these finding into D\&T, based on current research practices and relevant evidence, is best done through the visualization factor associated most prominently with spatial ability. The visualization factor, which as mentioned has seen some inclusion within 
D\&T related research, has been subject to a considerable about of investigation more broadly within science, technology, engineering and mathematics (STEM) subject areas. Longitudinal evidence links it to increased performance and interest in STEM areas (Wai et al. 2009) and a meta-analysis of spatial interventions indicates it is malleable and can be developed (Uttal et al. 2013). Perhaps the most prominent intervention for developing the visualization factor is a spatial skills curriculum that has been developed by Sorby over the last 2-3 decades (Sorby et al. 2018; Sorby and Baartmans 1996). It is posited here, due the evidence that education appears to be the most robust and durable method for developing intelligence, that the strength of Sorby's curriculum is that is it based on principles of education and does not resemble a "brain-training" game. This particular intervention is one way in which D\&T research and practice could benefit from further awareness of intelligence research, as this intervention could be explored relative to its impact on desirable D\&T outcomes and if found to be a positive impact, could be incorporated into practice.

Taking this a step further, recalling that the visualization factor is associated with fluid intelligence, the closest second-order factor to general intelligence, there is an apparent research agenda concerning the capacity of D\&T to impact students' fluid intelligence. Given that visualization can be benefited through an educational style intervention, this presents that at least a factor that has some shared variance with fluid intelligence can be developed in that way. First, for D\&T research it would be of interest to know if the spatial skill curriculum impacts the shared variance between spatial ability and fluid intelligence, or if it impacts the visualization factor but not fluid intelligence. Second, considering fluid intelligence as "the deliberate but flexible control of attention to solve novel, "on-the-spot" problems that cannot be performed by relying exclusively on previously learned habits, schemas, and scripts" (Schneider and McGrew 2012, p. 111), it appears auspiciously linked to D\&T practice with respect to the prevalence of design and engagement with technology related case studies where knowledge of the problem could be low. It is possible that some of the aspects of D\&T which make it unique (Buckley et al. 2018d) such as the applied and normative nature of technological knowledge and the prevalence of design within pedagogical practices could support D\&T learners in developing fluid abilities. This is something that D\&T researchers ought to be very interested in, as if the context of D\&T lends to intelligence development which is unique to what other subjects offer, that could be a considerable dimension to its purpose within national curricula.

\section{Concluding remarks}

"If there is anything that the last 100 years of social science research has taught us, it is that every person is a one-of-a-kind combination of genes and experience. Each person is unique and not equal to any other in the mathematical sense" (Detterman 2016, p. 2). D\&T education research to date has paid considerable attention to learners' experiences, but less so to their innate capacities. The primary innate capacity of learners which is considered in D\&T research is the human ability to design (Kimbell and Stables 2007; Stables 2008) which shares a number of characteristics with the intelligence construct in that it is difficult to define verbally (Newman 2017) and the likelihood that it contains multiple facets. Indeed, bridging the bodies of literature associated with design and intelligence could yield a sizable benefit. D\&T researchers pay considerable attention to design from a number of perspectives, and it is now advised that intelligence, both the broad $g$ factor and more specific cognitive abilities, feature more prominently in D\&T research. This should initially 
relate to the predictive capacity of intelligence factors for desirable D\&T student outcomes to identify factors which are contextually relevant, the interaction between intelligence and knowledge acquisition across various D\&T contexts, and the capacity for D\&T practices to benefit intellectual development. Each of these advances would have significant benefits for D\&T practices and for society as a whole. However, as highlighted at the beginning of this article, caution is warranted with respect to the misuse of such evidence to ensure it is not used in support of discriminatory educational practices. The core agenda must be to strive to make education accessible and beneficial for all learners relative to their individual needs and abilities.

Acknowledgements Open access funding provided by Royal Institute of Technology.

Open Access This article is licensed under a Creative Commons Attribution 4.0 International License, which permits use, sharing, adaptation, distribution and reproduction in any medium or format, as long as you give appropriate credit to the original author(s) and the source, provide a link to the Creative Commons licence, and indicate if changes were made. The images or other third party material in this article are included in the article's Creative Commons licence, unless indicated otherwise in a credit line to the material. If material is not included in the article's Creative Commons licence and your intended use is not permitted by statutory regulation or exceeds the permitted use, you will need to obtain permission directly from the copyright holder. To view a copy of this licence, visit http://creativecommons.org/licenses/by/4.0/.

\section{References}

Ang, S., \& van Dyne, L. (Eds.). (2008). Handbook of cultural intelligence: Theory, measurement, and applications. New York: M.E. Sharpe.

Atkinson, S. (2017). So what went wrong and why? In E. Norman \& K. Baynes (Eds.), Design epistemology and curriculum planning (pp. 13-17). London: Loughborough Design Press.

Barlex, D. (2019). Too much D not enough T? [Blog post]. David and Torben for D\&T. https://dandtforda ndt.wordpress.com/2019/07/06/too-much-d-not-enough-t/

Barlex, D., \& Steeg, T. (2017). Re-building Design \& Technology in the secondary school curriculum version 2: A working paper. D\&TforD\&T.

Baumert, J., Lüdtke, O., Trautwein, U., \& Brunner, M. (2009). Large-scale student assessment studies measure the results of processes of knowledge acquisition: Evidence in support of the distinction between intelligence and student achievement. Educational Research Review, 4(3), 165-176.

Bodner, G., \& Guay, R. (1997). The purdue visualization of rotations test. The Chemical Educator, 2(4), $1-17$.

Buckley, J., Seery, N., \& Canty, D. (2018a). A heuristic framework of spatial ability: A review and synthesis of spatial factor literature to support its translation into STEM education. Educational Psychology Review. https://doi.org/10.1007/s10648-018-9432-z.

Buckley, J., Seery, N., \& Canty, D. (2018b). Investigating the use of spatial reasoning strategies in geometric problem solving. International Journal of Technology and Design Education. https://doi.org/10.1007/ s10798-018-9446-3.

Buckley, J., Seery, N., Canty, D., \& Gumaelius, L. (2018c). Visualization, inductive reasoning, and memory span as components of fluid intelligence: Implications for technology education. International Journal of Educational Research, 90(1), 64-77. https://doi.org/10.1016/j.ijer.2018.05.007.

Buckley, J., Seery, N., Power, J., \& Phelan, J. (2018d). The importance of supporting technological knowledge in post-primary education: A cohort study. Research in Science \& Technological Education. https://doi.org/10.1080/02635143.2018.1463981.

Canivez, G., \& Youngstrom, E. (2019). Challenges to the Cattell-Horn-Carroll theory: Empirical, clinical, and policy implications. Applied Measurement in Education, 32(3), 232-248.

Carroll, J. (1991). Still no demonstration that $\mathrm{g}$ is not unitary: Further comment on Kranzler and Jensen. Intelligence, 15(4), 449-453.

Carroll, J. (1993). Human cognitive abilities: A survey of factor-analytic studies. Cambridge: Cambridge University Press. 
Carroll, J. (1997). Psychometrics, intelligence, and public perception. Intelligence, 24(1), $25-52$.

Cattell, R. (1943). The measurement of adult intelligence. Psychological Bulletin, 40(3), 153-193.

Cattell, R. (1963). Theory of fluid and crystallized intelligence: A critical experiment. Journal of Educational Psychology, 54(1), 1-22.

Cattell, R., \& Horn, J. (1978). A check on the theory of fluid and crystallized intelligence with description of new subtest designs. Journal of Educational Measurement, 15(3), 139-164.

de Vries, M. (2016). Teaching about technology: An introduction to the philosophy of technology for nonphilosophers. Berlin: Springer.

Deary, I. (2000). Looking down on human intelligence: From psychometrics to the brain. Oxford: Oxford University Press.

Detterman, D. (2016). Education and intelligence: Pity the poor teacher because student characteristics are more significant than teachers or schools. The Spanish Journal of Psychology, 19(e93), 1-11.

Ebisch, S., Perrucci, M., Mercuri, P., Romanelli, R., Mantini, D., Romani, G. L., et al. (2012). Common and unique neuro-functional basis of induction, visualization, and spatial relationships as cognitive components of fluid intelligence. NeuroImage, 62(1), 331-342.

Fitts, P., \& Posner, M. (1967). Human performance. Pacific Grove: Brooks/Cole Publishing Company.

Flynn, J. (1984). The mean IQ of Americans: Massive gains 1932 to 1978. Psychological Bulletin, 95(1), 29-51.

Frey, M., \& Detterman, D. (2004). Scholastic assessment or g? Psychological Science, 15(6), 373-378.

Gibson, K. (2008). Technology and technological knowledge: A challenge for school curricula. Teachers and Teaching, 14(1), 3-15.

Guay, R. (1977). Purdue spatial visualization test: Rotations. West Lafayette: Purdue Research Foundation.

Halpern, D. (1997). Sex differences in intelligence: Implications for education. American Psychologist, 52(10), 1091-1102. https://doi.org/10.1037/0003-066X.52.10.1091.

Halpern, D., \& LaMay, M. (2000). The smarter sex: A critical review of sex differences in intelligence. Educational Psychology Review, 12(2), 229-246.

Hambrick, D., Altmann, E., \& Burgoyne, A. (2018). A knowledge activation approach to testing the circumvention-of-limits hypothesis. American Journal of Psychology, 131(3), 307-321.

Hambrick, D., Libarkin, J., Petcovic, H., Baker, K., Elkins, J., Callahan, C., et al. (2012). A test of the circumvention-of-limits hypothesis in scientific problem solving: The case of geological bedrock mapping. Journal of Experimental Psychology: General, 141(3), 397-403.

Herrnstein, R., \& Murray, C. (1994). The bell curve: Intelligence and class structure in American life. New York: The Free Press.

Horn, J. (1985). Remodelling old models of intelligence. In B. Wolman (Ed.), Handbook of intelligence: theories, measurements, and applications (pp. 267-300). New Jersey: Wiley.

Horn, J., \& Blankson, B. (2005). Foundations for a better understanding of cognitive abilities. In D. Flanagan \& P. Harrison (Eds.), Contemporary intellectual assessment: theories, tests, and issues (2nd Ed., pp. 41-68). Guilford Press, New York

Horn, J., \& Cattell, R. (1966). Refinement and test of the theory of fluid and crystallized general intelligences. Journal of Educational Psychology, 57(5), 253-270.

Horn, J., \& Noll, J. (1997). Human cognitive capabilities: Gf-Gc theory. In D Flanagan, J. Genshaft, \& P. Harrison (Eds.), Contemporary intellectual assessment: theories, tests, and issues (1st Ed., pp. 53-91). Guilford Press, New York

Ingerman, A., \& Collier-Reed, B. (2011). Technological literacy reconsidered: A model for enactment. International Journal of Technology and Design Education, 21(2), 137-148.

Jensen, A. (1998). The g factor: The science of mental ability. Connecticut: Greenwood Publishing Group.

Johnson, W., \& Bouchard, T., Jr. (2005). The structure of human intelligence: It is verbal, perceptual, and image rotation (VPR), not fluid and crystallized. Intelligence, 33(4), 393-416.

Khoza, S. (2017). Difficulties in teaching and learning sectional drawing in a university based in the Eastern Cape, South Africa. In P. J. Williams \& D. Barlex (Eds.), Contemporary research in technology education: Helping teachers develop research-informed practice (pp. 89-103). Berlin: Springer.

Kimbell, R. (2007). E-assessment in project e-scape. Design and Technology Education: An International Journal, 12(2), 66-76.

Kimbell, R. (2011). Wrong ... but right enough. Design and Technology Education: An International Journal, 16(2), 6-7.

Kimbell, R. (2012). The origins and underpinning principles of e-scape. International Journal of Technology and Design Education, 22(2), 123-134.

Kimbell, R., Martin, G., Wharfe, W., Wheeler, T., Perry, D., Miller, S., et al. (2005). E-scape portfolio assessment: Phase 1 report. Goldsmiths: University of London. 
Kimbell, R., \& Stables, K. (2007). Researching design learning: Issues and findings from two decades or research and development. Netherlands: Springer.

Kimbell, R., Wheeler, T., Miller, S., \& Pollitt, A. (2007). E-scape portfolio assessment: Phase 2 report. Goldsmiths: University of London.

Kimbell, R., Wheeler, T., Stables, K., Shepard, T., Martin, F., Davies, D., et al. (2009). E-scape portfolio assessment: Phase 3 report. Goldsmiths: University of London.

Kirschner, P., Sweller, J., \& Clark, R. (2006). Why minimal guidance during instruction does not work: An analysis of the failure of constructivist, discovery, problem-based, experiential, and inquiry-based teaching. Educational Psychologist, 41(2), 75-86.

Koenig, K., Frey, M., \& Detterman, D. (2008). ACT and general cognitive ability. Intelligence, 36(2), $153-160$.

Kozhevnikov, M., \& Thornton, R. (2006). Real-time data display, spatial visualization ability, and learning force and motion concepts. Journal of Science Education and Technology, 15(1), 111-132.

Kvist, A., \& Gustafsson, J.-E. (2008). The relation between fluid intelligence and the general factor as a function of cultural background: A test of cattell's investment theory. Intelligence, 36(5), 422-436.

Liao, K.-H. (2017). The abilities of understanding spatial relations, spatial orientation, and spatial visualization affect 3D product design performance: Using carton box design as an example. International Journal of Technology and Design Education, 27(1), 131-147.

Lin, H. (2016). Influence of design training and spatial solution strategies on spatial ability performance. International Journal of Technology and Design Education, 2016(1), 123-131.

Major, J., Johnson, W., \& Deary, I. (2012). Comparing models of intelligence in Project TALENT: The VPR model fits better than the CHC and extended Gf-Gc models. Intelligence, 40(6), 543-559.

Maranto, R., \& Wai, J. (2020). Why intelligence is missing from american education policy and practice, and what can be done about it. Journal of Intelligence, 8(1), 1-12.

Mayer, J., \& Salovey, P. (1993). The intelligence of emotional intelligence. Intelligence, 17(4), 433-442.

Mayer, R. (2002). Rote versus meaningful learning. Theory into Practice, 41(4), 226-232.

McGrew, K. (2009). CHC theory and the human cognitive abilities project: Standing on the shoulders of the giants of psychometric intelligence research. Intelligence, 37(1), 1-10.

McLain, M. (2018). Emerging perspectives on "the demonstration" as a signature pedagogy in design and technology education. International Journal of Technology and Design Education, 28(4), 985-1000.

McLain, M. (2019). Developing perspectives on "the demonstration" as a signature pedagogy in design and technology education. International Journal of Technology and Design Education. https://doi. org/10.1007/s10798-019-09545-1.

Meehl, P. (2006). The power of quantitative thinking. In N. Waller, L. Yonce, W. Grove, D. Faust, \& M. Lenzenweger (Eds.), A Paul Meehl reader: essays on the practice of scientific psychology (pp. 433444). New Jersey: Erlbaum.

Mitcham, C. (1994). Thinking through technology: The path between engineering and philosophy. Chicago: Chicago University Press.

Mosing, M., Pedersen, N., Madison, G., \& Ullén, F. (2014). Genetic pleiotropy explains associations between musical auditory discrimination and intelligence. PLOS ONE, 9(11), e113875.

Neisser, U., Boodoo, G., Bouchard, T., Jr., Boykin, A., Brody, N., Ceci, S., et al. (1996). Intelligence: Knowns and unknowns. American Psychologist, 51(2), 77-101.

Newman, G. (2017). How we know, what we should know: The building blocks of cultural awareness in design education. In E. Norman \& K. Baynes (Eds.), Design epistemology and curriculum planning (pp. 28-31). London: Loughborough Design Press.

Norman, E. (2017). Design epistemology and curriculum planning. In E. Norman \& K. Baynes (Eds.), Design and technology education: An international journal. London: Loughborough Design Press.

Nusbaum, E., \& Silvia, P. (2011). Are intelligence and creativity really so different? Fluid intelligence, executive processes, and strategy use in divergent thinking. Intelligence, 39(1), 36-45.

O'Connell, M. (2018). The power of cognitive ability in explaining educational test performance, relative to other ostensible contenders. Intelligence, 66(1), 122-127.

Owen, A., Hampshire, A., Grahn, J., Stenton, R., Dajani, S., Burns, A., et al. (2010). Putting brain training to the test. Nature, 465(7299), 775-778.

Pollitt, A. (2012a). Comparative judgement for assessment. International Journal of Technology and Design Education, 22(2), 157-170.

Pollitt, A. (2012b). The method of adaptive comparative judgement. Assessment in Education: Principles, Policy \& Practice, 19(3), 281-300.

Primi, R., Ferrão, M. E., \& Almeida, L. (2010). Fluid intelligence as a predictor of learning: A longitudinal multilevel approach applied to math. Learning and Individual Differences, 20(5), 446-451.

Ritchie, S. (2015). Intelligence: All that matters. London: John Murray Learning. 
Ritchie, S., \& Tucker-Drob, E. (2018). How much does education improve intelligence? A meta-analysis. Psychological Science, 29(8), 1358-1369.

Salthouse, T. (1991). Expertise as the circumvention of human processing limitations. In K. A. Ericsson \& J. Smith (Eds.), Toward a general theory of expertise: Prospects and limits (pp. 286-300). Cambridge: Cambridge University Press.

Savi, A., Marsman, M., van der Maas, H., \& Maris, G. (2019). The wiring of intelligence. Perspectives on Psychological Science, 14(6), 1034-1061.

Schneider, J., \& McGrew, K. (2012). The Cattell-Horn-Carroll model of intelligence. In D. Flanagan \& P. Harrison (Eds.), Contemporary intellectual assessment: theories, tests, and issues (3rd ed., pp. 99-144). Guilford Press, New York

Schneider, J., \& McGrew, K. (2018). The Cattell-Horn-Carroll theory of cognitive abilities. In D. Flanagan \& E. McDonough (Eds.), Contemporary intellectual assessment: theories, tests, and issues. New York: The Guilford Press.

Seery, N., Kimbell, R., Buckley, J., \& Phelan, J. (2019). Considering the relationship between research and practice in technology education: A perspective on future research endeavours. Design and Technology Education: An International Journal, 24(2), 1-12.

Simons, D., Boot, W., Charness, N., Gathercole, S., Chabris, C., Hambrick, D., et al. (2016). Do "braintraining" programs work? Psychological Science in the Public Interest, Supplement, 17(3), 103-186.

Smith-Woolley, E., Pingault, J.-B., Selzam, S., Rimfeld, K., Krapohl, E., von Stumm, S., et al. (2018). Differences in exam performance between pupils attending selective and non-selective schools mirror the genetic differences between them. Npj Science of Learning, 3(3), 1-7.

Sorby, S., \& Baartmans, B. (1996). A course for the development of 3-D spatial visualization skills. Engineering Design Graphics Journal, 60(1), 13-20.

Sorby, S., Veurink, N., \& Streiner, S. (2018). Does spatial skills instruction improve STEM outcomes? The answer is "yes". Learning and Individual Differences, 67(1), 209-222.

Spearman, C. (1904). "General intelligence", objectively determined and measured. The American Journal of Psychology, 15(2), 201-292.

Spendlove, D. (2017). Design thinking: What is it and where might it reside? In E. Norman \& K. Baynes (Eds.), Design epistemology and curriculum planning (pp. 39-42). Londo: Loughborough Design Press.

Stables, K. (2008). Designing matters; Designing minds: The importance of nurturing the designerly in young people. Design and Technology Education: An International Journal, 13(3), 8-18.

Sternberg, R. (2000). The concept of intelligence. In R. Sternberg (Ed.), Handbook of intelligence (pp. 3-15). Cambridge: Cambridge University Press.

Sternberg, R. (2019). A theory of adaptive intelligence and its relation to general intelligence. Journal of Intelligence, 7(4), 1-17.

Sternberg, R., Forsythe, G., Hedlund, J., Horvath, J., Wagner, R., Williams, W., et al. (2000). Practical intelligence in everyday life. Cambridge: Cambridge University Press.

Stieff, M. (2007). Mental rotation and diagrammatic reasoning in science. Learning and Instruction, 17(2), 219-234.

Thorndike, R., \& Stein, S. (1937). An evaluation of the attempts to measure social intelligence. Psychological Bulletin, 34(5), 275-285.

Trahan, L., Stuebing, K., Hiscock, M., \& Fletcher, J. (2014). The Flynn effect: A meta-analysis. Psychological Bulletin, 140(5), 1332-1360.

Tucker-Drob, E. (2009). Differentiation of cognitive abilities across the life span. Developmental Psychology, 45(4), 1097-1118.

Uttal, D., Meadow, N., Tipton, E., Hand, L., Alden, A., Warren, C., et al. (2013). The malleability of spatial skills: A meta-analysis of training studies. Psychological Bulletin, 139(2), 352-402.

von Mengersen, B. (2017). Hyper design thinking: Critique, praxis and reflection. In P. J. Williams \& K. Stables (Eds.), Critique in design and technology education (pp. 301-320). Berlin: Springer Nature.

Voyer, D., Voyer, S., \& Saint-Aubin, J. (2017). Sex differences in visual-spatial working memory: A metaanalysis. Psychonomic Bulletin and Review, 24(2), 307-334.

Wai, J., Lubinski, D., \& Benbow, C. (2009). Spatial ability for STEM domains: Aligning over 50 years of cumulative psychological knowledge solidifies its importance. Journal of Educational Psychology, 101(4), 817-835.

Williams, P. J. (2000). Design: The only methodology of technology? Journal of Technology Education, $11(2), 48-60$.

Williams, P. J. (2009). Technological literacy: A multliteracies approach for democracy. International Journal of Technology and Design Education, 19(3), 237-254. 
Williams, P. J., \& Barlex, D. (Eds.). (2017). Contemporary research in technology education: Helping teachers develop research-informed practice. Berlin: Springer.

Williams, P. J., \& Barlex, D. (Eds.). (2019). Explorations in technology education research: Helping teachers develop research informed practice. Berlin: Springer.

Williams, P. J., Jones, A., \& Buntting, C. (Eds.). (2015). The future of technology education. Berlin: Springer.

Xu, M., Williams, P. J., Gu, J., \& Zhang, H. (2019). Hotspots and trends of technology education in the International Journal of Technology and Design Education: 2000-2018. International Journal of Technology and Design Education. https://doi.org/10.1007/s10798-019-09508-6.

Publisher's Note Springer Nature remains neutral with regard to jurisdictional claims in published maps and institutional affiliations. 